\title{
The sensitivity of catchment runoff models to rainfall data at different spatial scales
}

\author{
V.A. Bell and R.J. Moore \\ Centre for Ecology and Hydrology, Wallingford, Oxfordshire, OX10 8BB, UK \\ e-mail for corresponding author: vib@ceh.ac.uk
}

\section{Abstract}

\begin{abstract}
The sensitivity of catchment runoff models to rainfall is investigated at a variety of spatial scales using data from a dense raingauge network and weather radar. These data form part of the HYREX (HYdrological Radar EXperiment) dataset. They encompass records from 49 raingauges over the $135 \mathrm{~km}^{2}$ Brue catchment in south-west England together with 2 and $5 \mathrm{~km}$ grid-square radar data. Separate rainfall time-series for the radar and raingauge data are constructed on 2,5 and $10 \mathrm{~km}$ grids, and as catchment average values, at a 15 minute time-step. The sensitivity of the catchment runoff models to these grid scales of input data is evaluated on selected convective and stratiform rainfall events. Each rainfall time-series is used to produce an ensemble of modelled hydrographs in order to investigate this sensitivity. The distributed model is shown to be sensitive to the locations of the raingauges within the catchment and hence to the spatial variability of rainfall over the catchment. Runoff sensitivity is strongest during convective rainfall when a broader spread of modelled hydrographs results, with twice the variability of that arising from stratiform rain. Sensitivity to rainfall data and model resolution is explored and, surprisingly, best performance is obtained using a lower resolution of rainfall data and model. Results from the distributed catchment model, the Simple Grid Model, are compared with those obtained from a lumped model, the PDM. Performance from the distributed model is found to be only marginally better during stratiform rain $\left(R^{2}\right.$ of 0.922 compared to 0.911 ) but significantly better during convective rain $\left(R^{2}\right.$ of 0.953 compared to 0.909$)$. The improved performance from the distributed model can, in part, be accredited to the excellence of the dense raingauge network which would not be the norm for operational flood warning systems. In the final part of the paper, the effect of rainfall resolution on the performance of the $2 \mathrm{~km}$ distributed model is explored. The need to recalibrate the model for use with rainfall data of a given resolution, particularly for periods of convective rain, is highlighted. Again, best performance is obtained using lower resolution rainfall data. This is interpreted as evidence for the need to improve the distributed model structure to make better use of the higher resolution information on rainfall and topographic controls on runoff. Degrading the resolution of rainfall data, model or both to achieve the smoothing apparently needed is not seen as wholly appropriate.
\end{abstract}

Keywords: rainfall, runoff, sensitivity, scale, model, flood

\section{Introduction}

A key question of hydrological science is how spatial variability in rainfall impacts on the flow response at the catchment scale. This question has important practical implications in terms of the accuracy of flood predictions from catchment runoff models which use data from a network of raingauges as input. Such flood predictions may underpin flood warning procedures operated in real-time or form a key role in the design and planning of flood defence measures. The utility of weather radars, as a complement to raingauge networks, will also be governed by the importance of rainfall variability on flood response.

The purpose of this paper is to employ a unique dataset, encompassing information from a dense raingauge network and a weather radar, together with lumped and distributed rainfall-runoff models to investigate how spatial variability in rainfall impacts on flood response at the catchment scale.
The results obtained are of practical relevance to the design of networks of raingauges and radars for hydrological use where the accuracy of flood predictions from rainfall-runoff models is a primary concern.

The issue of how rainfall variability impacts on flood response has been investigated by a number of researchers within a rainfall-runoff modelling framework; Singh (1997) provides a recent review. Many have focused on the construction of simulation experiments in order to understand the variability of runoff to rainfall and other factors (Wood et al., 1988; Watts and Calver, 1991). However, relatively few investigators have had the benefit of detailed data on patterns of storm rainfall obtained from dense raingauge networks and from weather radar. A recent exception, but without the benefit of weather radar, is the sensitivity study reported by Obled et al. (1994). Whilst they see significant spatial variability in the rainfall, much less variability is observed in the runoff, at a catchment scale of $71 \mathrm{~km}^{2}$, due 
to smoothing and damping effects. Others have provided valuable empirical evidence for particular environments. For example, Faurès et al. (1995) investigated runoff response from a small scale $(4.4 \mathrm{ha})$ semi-arid catchment dominated by convective rainfall, and found that use of a single raingauge can lead to large uncertainties in runoff estimation. Pessoa et al. (1993) and Bell and Moore (1998b) provide some indication of the errors arising from the use of distributed and areal average radar data, or data from a single raingauge, as input to a rainfall-runoff model for flood forecasting. An important feature of the present study is the use of data from a dense raingauge network and weather radar to quantify empirically the variability in rainfall and modelled runoff response. This is done for both stratiform and convective rainfall periods for a catchment scale of $135 \mathrm{~km}^{2}$ in an area of modest hills and having a humid temperate climatic regime (southern Britain).

The sensitivity of both lumped and distributed catchment runoff models to rainfall estimates at a variety of spatial scales is examined. The investigation divides into three parts. In the first part, the sensitivity of the distributed model-the Simple Grid Model (SGM) - to rainfall variability over the catchment is assessed using both radar and raingauge data. Ensembles of hydrographs are obtained using both radar and raingauge rainfall estimates for each of $28,2 \mathrm{~km}$ radar grid squares located within the catchment. The results quantify the greater variability in rainfall hyetographs and flow hydrographs during convective than in stratiform rain. In the second part of the investigation, the performance of the distributed catchment model is assessed at a 2, 5 and $10 \mathrm{~km}$ model resolution using rainfall data of the same resolution, again for both convective and stratiform rainfall events. Results are compared with those obtained using a lumped catchment runoff model, the Probability Distributed Moisture (PDM) model. In the third, and final, part, different resolutions of grid-square rainfall estimated from the dense-raingauge network are used with the distributed model, configured on a $2 \mathrm{~km}$ grid, to establish how model performance varies with rainfall resolution under convective and stratiform rain.

\section{Background}

\section{THE HYREX DATASET}

Under the HYREX (HYdrological Radar EXperiment) Special Topic Programme of the Natural Environment Research Council, a dense network of 49 tipping-bucket raingauges was installed within the Brue catchment in Somerset, south-west England. This catchment has an area of $135 \mathrm{~km}^{2}$ to its gauging station at Lovington and is predominantly rural with modest relief. The closest weather radar to the catchment is at Wardon Hill in Dorset, about $40 \mathrm{~km}$ to the south.

This C-band radar is part of the national radar network (Collier, 1996) and provides data on a $2 \mathrm{~km}$ grid out to a range of $76 \mathrm{~km}$ and on a $5 \mathrm{~km}$ grid outwards to $210 \mathrm{~km}$. The configuration of the raingauge network is such that 19 of the raingauges are located singly near the centre of each $2 \mathrm{~km}$ radar grid square and there are two SW-NE lines of 4 squares each containing two raingauges. In addition, there are two grid squares each containing 8 raingauges in areas of low and high relief. The raingauge network along with the relief of the catchment are shown in Fig. 1.

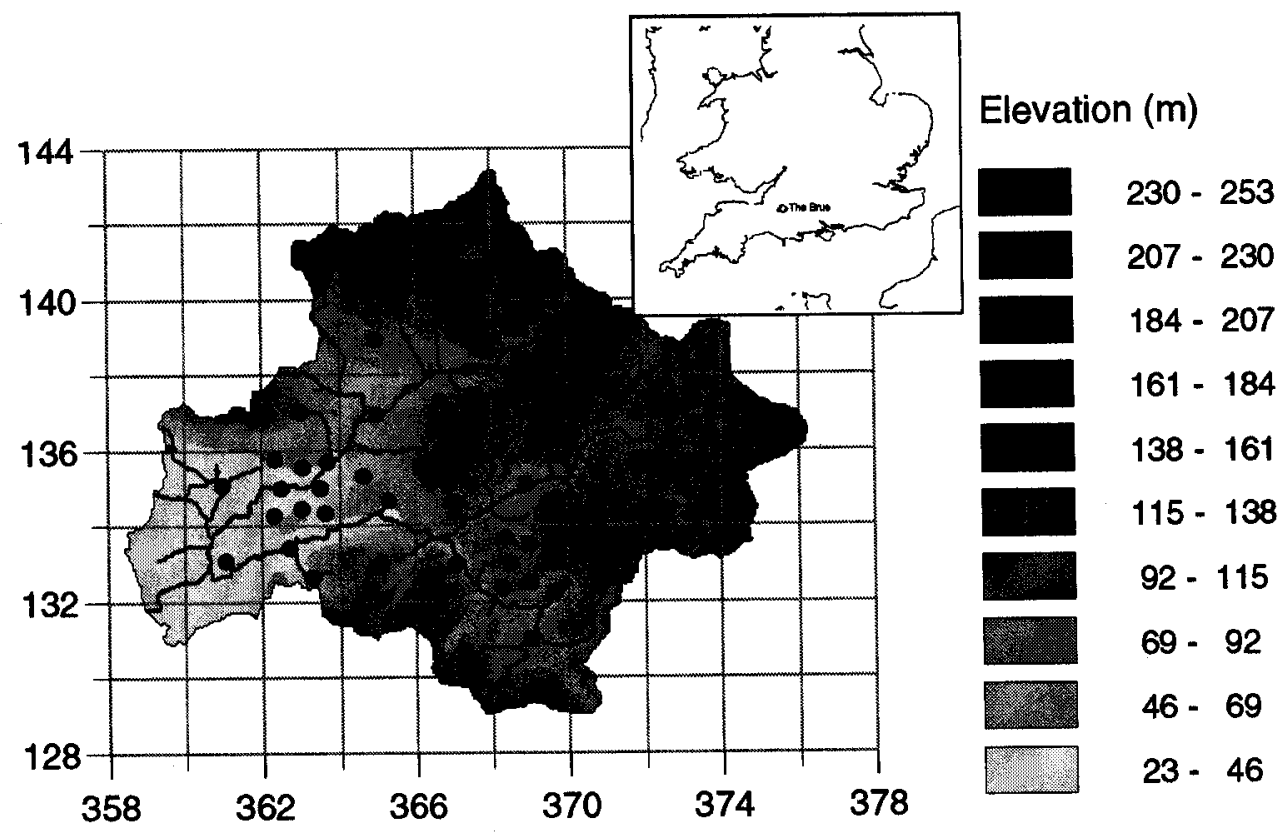

Fig. 1. Relief map for the Brue catchment showing the river network and the positions of the 49 raingauges (black dots). The inset map shoms the location of the Brue catchment in southern Britain. 
Intensive quality control of the raw raingauge and radar data collected under HYREX was carried out to identify and remove erroneous values (Wood et al., 2000). Data from the dense raingauge network have been used to construct 15 minute, $2 \mathrm{~km}$ grid square and catchment average rainfall estimates for the four year period 1993 to 1997 . The $2 \mathrm{~km}$ grid square estimates are formed for each of the 28 squares containing at least one raingauge; estimates are single gauge values or the average of 2 or $\mathbf{8}$ gauge values (or fewer if data are missing) depending on the number of gauges in each square. An average of these $2 \mathrm{~km}$ grid square estimates is used as the catchment average rainfall. Aggregates of the $2 \mathrm{~km}$ grid square estimates, for grids of 5 and $10 \mathrm{~km}$, have also been constructed to explore the effect of spatial rainfall and model resolution on catchment-scale runoff response. Also rainfall estimates for grid scales of 2, 4, 6, 8, 10 and $16 \mathrm{~km}$ are used later to explore the sensitivity of modelled runoff to the spatial scale of rainfall input. Alternative rainfall estimators have not been investigated, such as inclusion of neighbouring pixel values in a weighting scheme to obtain a more accurate (and also globally smoother) pixel estimate. A time-step of 15 minutes, corresponding to that normally available operationally for flood warning, is used throughout. The frequent model updating this allows can prove advantageous for flood forecasting applications (Austin and Moore, 1996).

\section{THE RAINFALL-RUNOFF MODELS}

Both a distributed catchment model configured on the radar grid and a lumped model of the catchment have been used in the sensitivity studies. Uniform rainfall (provided by a catchment average) and distributed grid rainfall have both been used with the distributed model. The distributed model used is the SGM (Bell and Moore, 1998a, b; Moore et al., 1994). This is a simple grid-based rainfall-runoff model designed for use with grid-square weather radar data; it is a conceptually rather than physically based distributed model. Figure 2 shows a schematic of the model structure. Each grid square in the catchment is conceptualised as a storage which receives water in the form of precipitation and loses water via evaporation, overflow and drainage. The following linkage function is used to relate the water capacity of the storage, $S_{\max }$, to the average topographic gradient within the grid square, $\bar{g}$ :

$$
S_{\max }=\left(1-\frac{\bar{g}}{g_{\max }}\right) c_{\max }
$$

for $\bar{g} \leq g_{\max }$. The parameters $g_{\max }$ and $c_{\max }$ are upper limits of gradient and storage capacity respectively and act as 'regional parameters' for the catchment model. Underlying this formulation is the premise that steeper slopes are less able to absorb water and thus generate runoff more readily. The absorption mechanism could relate to a combination of vegetation, surface detention and soil properties which might all be expected in some way to be influenced by topographic gradient. The maximum storage capacity parameter, $c_{\max }$, is obtained here by calibration but might be inferred from information on surveys of soil, and possibly of land use and geology. A digital terrain model (DTM) is used to obtain the mean topographic gradient, $\bar{g}$, for each grid-square within the catchment and $g_{\max }$ is taken to be the maximum of these values; here the CEH Wallingford DTM with a grid size of $50 \mathrm{~m}$ is used (Morris and Flavin, 1990). When the storage fills and overflows, this 'direct runoff' is routed via fast response pathways to the basin outlet. Water drains from the base of the storage in proportion to the volume stored, $S$, and is routed to the basin outlet via slow response pathways. Specifically, the drainage rate from the

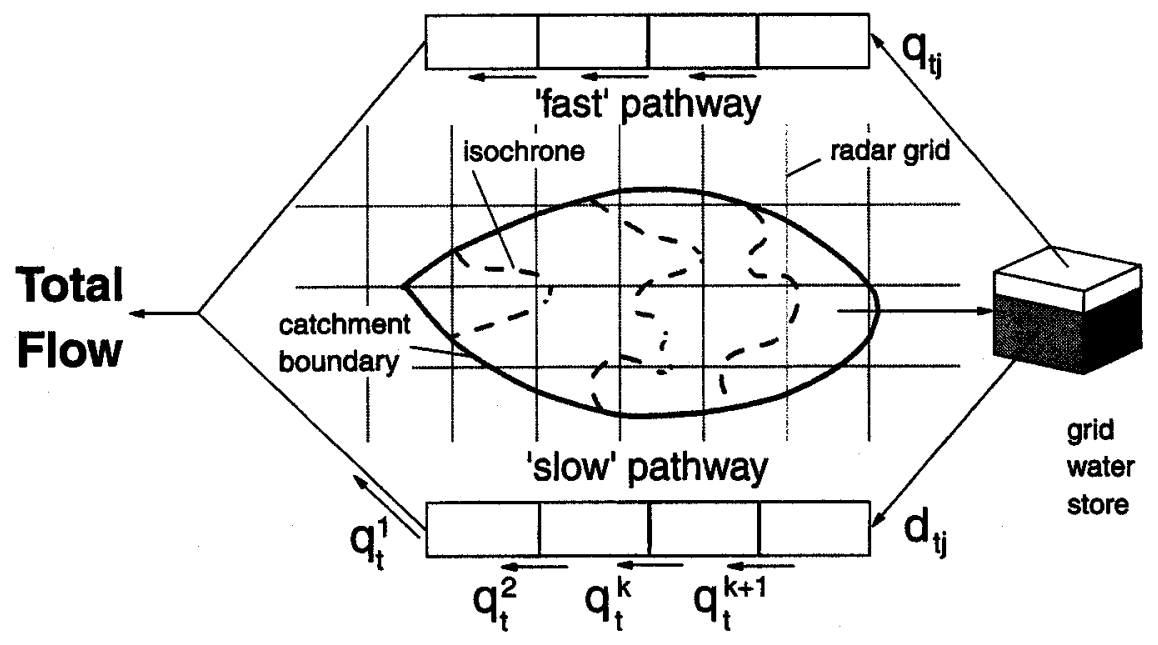

Fig. 2. The structure of the Simple Grid Model. 
storage is governed by the relation

$$
d=\left\{\begin{array}{r}
k_{d} S^{\beta}, \quad S>0 \\
0, \text { otherwise }
\end{array}\right.
$$

where $k_{d}$ is the drainage storage constant and the drainage exponent $\beta$ is a parameter (set here to 3 ). Water loss by evaporation is also in proportion to the water stored, declining linearly (or according to a power function) from the potential value once the water deficit, $S_{\max }-S$, falls below the root constant value.

Routing of water to the basin outlet via the fast and slow response pathways is represented by two cascades of kinematic wave routing reaches in parallel. Each routing reach is configured to be coincident with an isochrone band and, because of the discrete formulation in space and time, is able to accommodate both advective and diffusive translation effects. The construction of isochrones-lines joining points of equal time of travel to the basin outlet-is achieved by assuming that water travels with only two velocities depending on whether it is associated with a hillslope or is in a river channel. Again, a DTM is used to obtain the path lengths for hillslope and channel path types used in the derivation of the isochrones. Fast and slow response pathways share the same isochrone-based spatial configuration but are characterised by different kinematic wave speEds. Specifically, the $n$ isochrone strips within the catchment define the spatial configuration of a cascade of $n$ reaches, with the outflow from the $k$ th reach at time $t$ represented by

$$
q_{t}^{k}=(1-\theta) q_{t-1}^{k}+\theta\left(q_{t-1}^{k+1}+r_{t}^{k}\right)
$$

Here, $r_{t}^{k}$ is the outflow rate (fast direct runoff or slow drainage) from the $k$ th isochrone strip calculated for the interval $(t-1, t)$ and serves as the lateral inflow to the $k$ th reach. Parameter $\theta$ is a dimensionless wave speed taking values in the range 0 to 1 . The flow rate $q_{t}^{1}$ corresponds to the outflow (fast or slow response component) from the catchment.

The basic Grid Model has five main parameters that are always used in model calibration: the hillslope and river channel velocities which determine the number of isochrones, the wave speeds for routing direct runoff and drainage, and the drainage function storage constant. The initialisation parameter for soil moisture, $S_{0}$, and a rainfall correction factor, $f_{r}$, may also be used. Estimation of the regional parameters $g_{\max }$ and $c_{\max }$ have been discussed previously. All these parameters are invariant across the catchment. Spatial variation is introduced through the use of (i) DTM elevation data for estimating storage capacity from mean topographic gradient for each grid square, and (ii) DTM land and river flow path lengths for deriving isochrones used in translating water to the basin outlet.

The SGM can be configured for use with any resolution of grid-square rainfall data. Also, the model itself can be configured to use model grids of any spatial scale. This functionality is used here to investigate the effect of model grid size on runoff at the catchment scale for grid sizes of 2 , 5 and $10 \mathrm{~km}$; results are obtained using both spatially distributed rainfall and uniform rainfall, provided by a catchment average. A 15 minute time interval is used throughout for both the data and model time-step.

The lumped rainfall-runoff model employed is the PDM, or Probability Distributed Moisture, model (Moore, 1985, 1999; Institute of Hydrology, 1992, 1996). The PDM is a conceptual rainfall-runoff model which uses a probability distribution to describe the spatial variation of water storage capacity across a catchment. Saturation excess runoff generated at any point in the catchment is integrated over the catchment to give the total direct runoff entering fast response pathways to the basin outlet. Drainage from the soil enters slow response pathways. Storage routing representations of the fast and slow response pathways yields a fast and slow ('baseflow') response at the basin outlet which, when summed, gives the total basin flow.

The PDM model configuration used here employs a Pareto distribution of storage capacity (Moore, 1999), referred to by Moore (1985) as the reflected power distribution. This has the distribution function

$$
F(c)=1-\left(1-c / c_{\max }\right)^{b} \quad 0 \leq c \leq c_{\max }
$$

where parameter $c_{\max }$ is the maximum storage capacity in the basin, and parameter $b$ controls the degree of spatial variability of storage capacity, $c$, over the basin. Note that the rectangular distribution is obtained as a special case when $b=1$, and $b=0$ implies a constant storage capacity over the entire basin. The probability distributed principle of runoff production (Moore, 1985) applied to this distribution provides a means of establishing the proportion of the catchment that is saturated and generating runoff and can be used to compute the volume of direct runoff and change in water storage within each time-step via simple analytical expressions (Moore, 1999). Losses from the distributed stores via evaporation and drainage to groundwater vary as functions of catchment water storage, $S(t)$. Evaporation declines from the potential rate as a power function of the water storage deficit. A power-law drainage function

$$
d_{i}=k_{r}\left(S(t)-S_{t}\right)^{b_{r}}
$$

is used where $k_{r}$ is a drainage time constant with units of inverse time, $b_{r}$ is an exponent (usually set to 1 ) and $S_{t}$ is the threshold storage below which there is no drainage, water being held under soil tension. Translation of drainage via the slow response pathway is represented by a cubic storage function, whilst direct runoff translated via the fast response pathway uses a transfer function model discretely coincident with a cascade of two linear reservoirs (O'Connor, 1982). The sum of the two translated flows gives the runoff at the catchment outlet.

Both the SGM and the PDM are configured for use with 
the generic Model Calibration Shell of the River Flow Forecasting System or RFFS (CEH Wallingford, 2000), which is used to calibrate models off-line in preparation for their use in operational flood forecasting. The calibration procedure consists of inspection and manual adjustment of model parameters, aided by an interactive visualisation tool, followed by automatic optimisation minimising a chosen objective function. In this case the objective function used was the sum of the square of the differences between the observed flow, $Q_{i}$, and modelled flow, $q_{\mathrm{t}}$, at each time step, $t$; that is, $\mathcal{F}=\sum \varepsilon_{t}^{2}$, where the model error $\varepsilon_{t}=Q_{t}-q_{t}$ and the summation is computed over $n$ values. The main criteria used for assessment were the root mean square error (rmse) and the $\mathrm{R}^{2}$ statistic, the latter indicating the proportion of the variance in the original observations accounted for by the model.

\section{Assessments of model sensitivity}

\section{INTRODUCTION}

Both the PDM and, in particular, the distributed SGM have been used to assess the sensitivity of rainfall-runoff models to model and rainfall resolution and rainfall variability in convective and stratiform rainfall situations. The investigation has been split into three parts which are addressed in turn after a brief description of the rainfall periods used in the sensitivity study. The three parts relate to model sensitivity to (i) rainfall variability over the catchment, (ii) model and rainfall resolution, and (iii) rainfall data at different spatial scales.

\section{RAINFALL PERIODS USED FOR ASSESSMENT}

The sensitivity of the distributed rainfall-runoff model to the spatial resolution of rainfall data was investigated for periods of predominantly stratiform and convective rain from 20 January to 1 March 1995 and 20-29 May 1994 respectively.

\section{Fanuary to 1 March 1995}

The period of stratiform rain was associated with heavy rain affecting south and west Britain, with several rivers on flood alert. A depression crossed Britain on 19 January 1995 causing heavy gales and gusting over the next four days. February was wet and mild and mostly affected by south westerlies, with a westerly gale in south-west Britain on 16 February, and squally showers bringing thunder, snow and gusts on the 22nd. Temperatures were above average for the time of year. The Wardon Hill radar failed to record data intermittently during January so the investigation has been restricted to the period 6 February to 1 March.

\section{0-29 May 1994}

The period from 20 to 29 May 1994 experienced episodes of convective activity. An anticyclone was located over Iceland until 27 May with low pressure over southern Britain bringing predominantly easterly winds, cloudy conditions and heavy rain at times with some thunderstorms. Daytime temperatures were warm, although mean temperatures were $1{ }^{\circ} \mathrm{C}$ below normal for May. Rainfall conditions were variable over the Brue catchment with convective activity bringing showers and thunder on 22 and 23 May, stratiform rain on 21 and $26 \mathrm{May}$, and mixed convective and stratiform rain on 25 May.

\section{MODEL SENSITIVITY TO RAINFALL VARIABILITY OVER THE CATCHMENT}

The sensitivity of modelled catchment runoff to rainfall variability over the Brue catchment was investigated using data from the dense raingauge network and the Wardon Hill weather radar. Figures 3 (a) and (b) compare cumulative hyetographs obtained using raingauge and radar data for all 28 of the grid squares in the Brue that contain one or more raingauges. The periods shown are

(a) 21-22 May 1994: convective rain

(b) 21-22 January 1995: stratiform rain.

The raingauge hyetographs highlight the greater spatial variability in rainfall during the convective period, with a larger range of grid square totals seen for the end of the two day period of rainfall. The radar hyetographs do not appear at first to support this observation due to the radar underestimating rainfall over the convective period. But the greater spatial variability in the rainfall becomes apparent when rainfall is scaled up to compensate for problems with the radar hard ware calibration. No attempt to correct for the rainfall estimation bias is attempted here. However, it is worth noting that a simple static scaling adjustment is made implicitly as part of the calibration of the rainfall-runoff models, via the 'rainfall correction factor' parameter. Radar and gauge estimates for the stratiform period are broadly similar and consistent, although radar estimates display a wider range.

To determine the effect of rainfall variability on flow response at the catchment scale, rainfall estimates for each of the $28,2 \mathrm{~km}$ squares containing raingauges were used as alternative inputs to rainfall-runoff models to obtain an ensemble of 28 hydrographs. A further hydrograph was obtained using as input uniform rainfall calculated as a catchment average. The procedure followed is set down below.

(i) The Grid Model at a resolution of $2 \mathrm{~km}$ was calibrated on two periods for which there were substantial and isolated flow peaks. These were:

20-24 May 1994: predominantly convective rain, 3-8 January 1995: stratiform rain.

(ii) The model was calibrated separately for each event and for each type of rainfall input (radar and raingauge) to 
(a) Convective rain, 21-22 May 1994

Raingauge

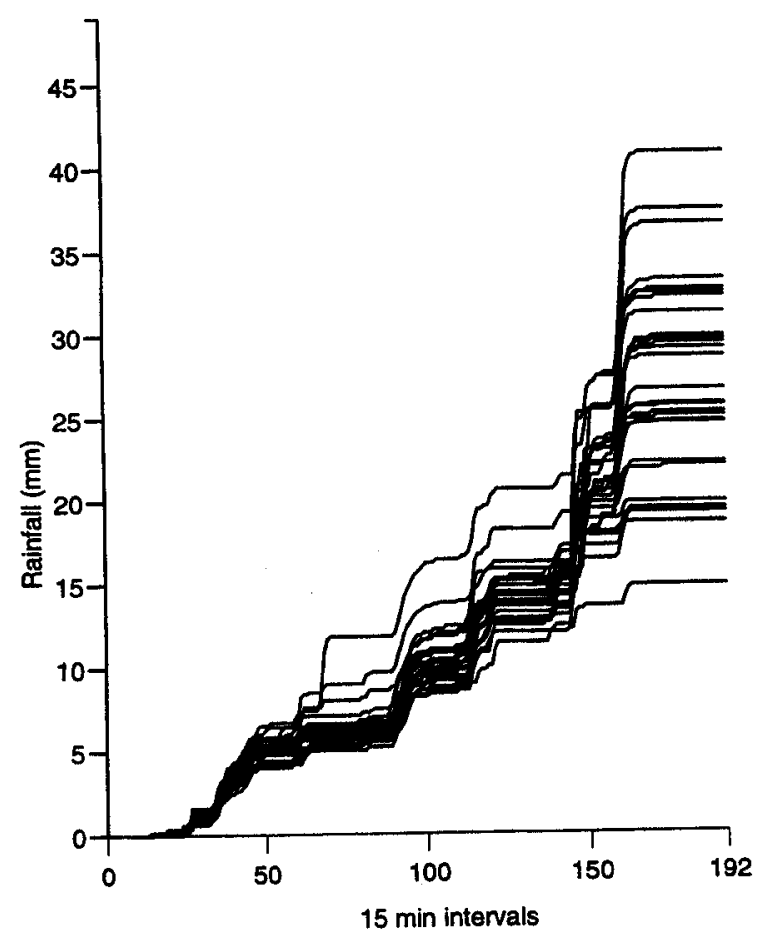

(b) Stratiform rain, 21-22 January 1995

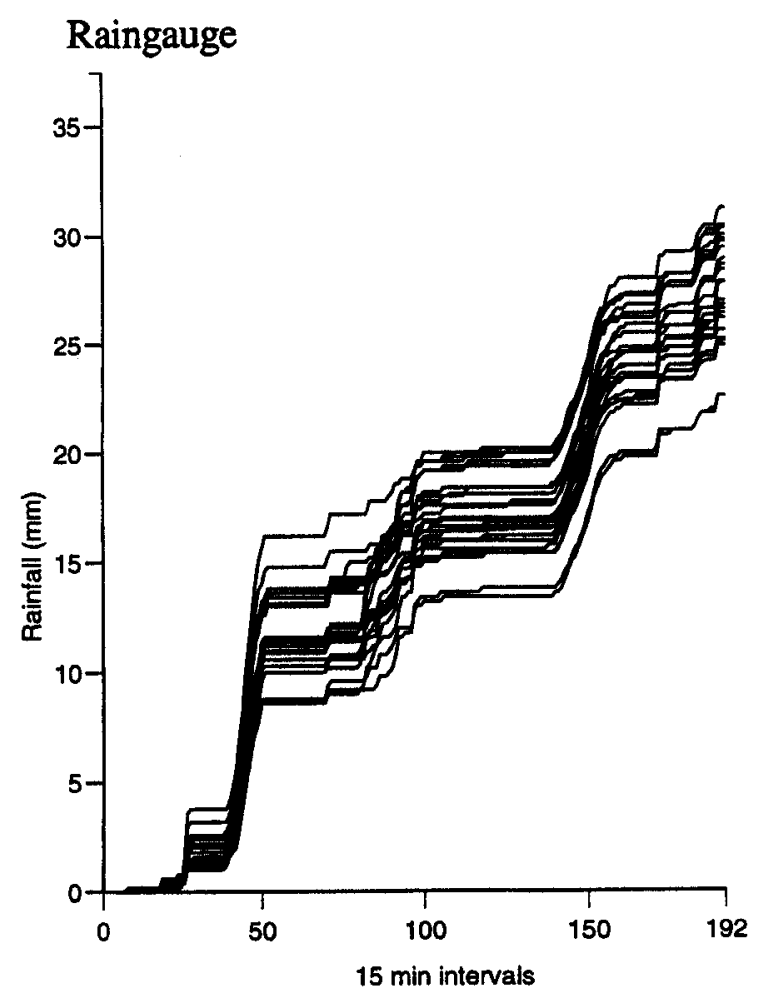

Radar

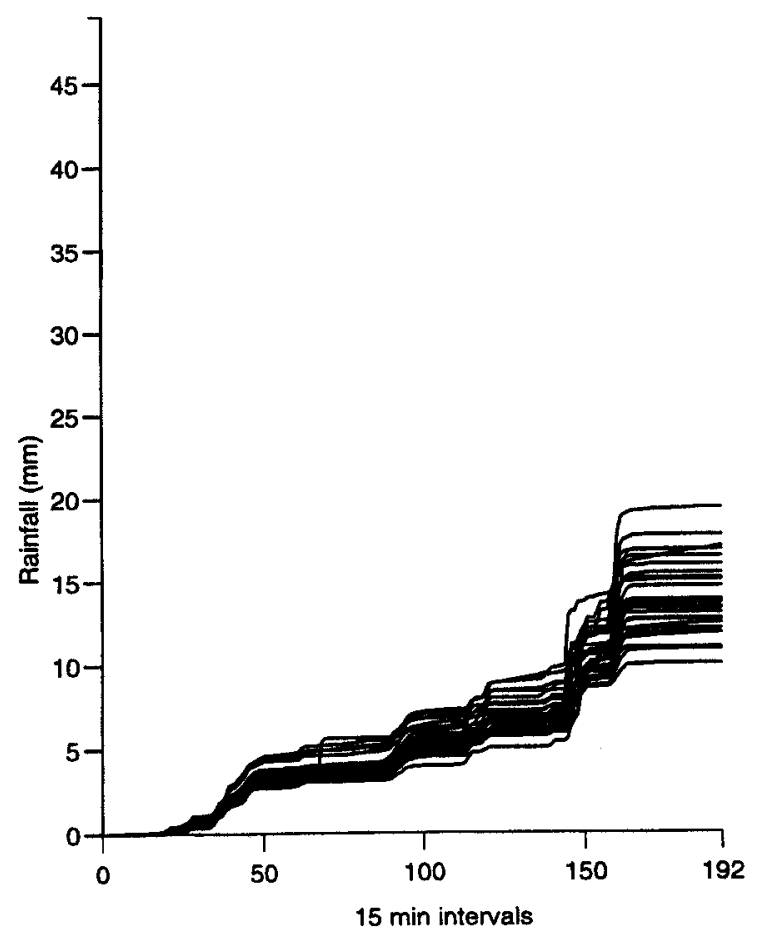

Radar

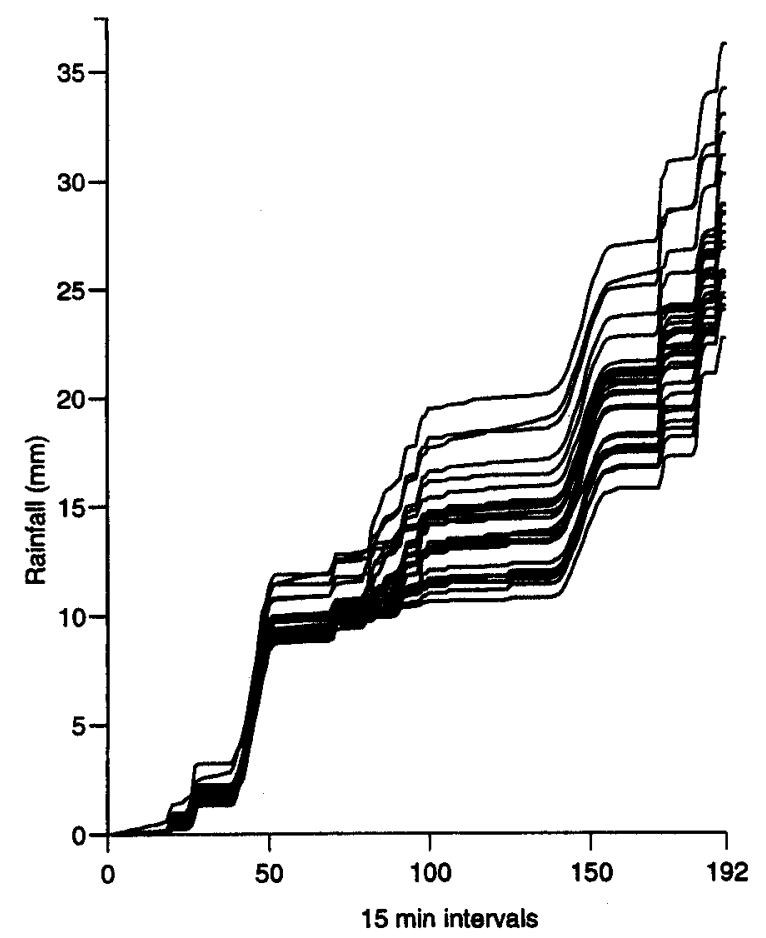

Fig. 3. Cumulative raingauge and radar hyetographs for grid squares containing raingauges in the Brue catchment for periods of convective and stratiform rain. 
obtain the best possible simulation in each case. Hence a total of four sets of model parameters was obtained.

(iii) Using the calibration parameters already obtained, a rainfall (radar or gauge) estimate for each $2 \mathrm{~km}$ square containing raingauges (an average if more than one gauge is present) was used as input to the Grid Model, assuming it to be an estimate for the catchment.

Catchment average rainfall data (provided as uniform rainfall on the $2 \mathrm{~km}$ model grid) were used for model calibration in all but one case. The exception was for the May 1994 period with raingauge data, when distributed $2 \mathrm{~km}$ data gave the best model performance. Good model performance was obtained for both periods when using raingauge data with $R^{2}$ values of 0.97 and 0.98 for the predominantly convective and stratiform periods respectively. Whilst good model performance using radar data was obtained for the convective period $\left(\mathrm{R}^{2}=0.98\right)$, the performance was less good for the stratiform period $\left(R^{2}=0.88\right)$ with a spurious secondary flow peak being generated in the recession on 6 January.

The resulting ensembles of hydrographs are shown in Figs. 4 and 5. Graphs (a) show the set of hydrographs resulting from raingauge data, and graphs (b) show the corresponding radar results. The range of flow hydrographs for the May 1994 period of convective rain is quite extreme, peak flows varying from 1 to $45 \mathrm{~m}^{3} \mathrm{~s}^{-1}$ when alternative raingauges are used to provide rainfall estimates while the observed flow peak is $10 \mathrm{~m}^{3} \mathrm{~s}^{-1}$. This wide span of hydrographs results in $R^{2}$ statistics ranging from 0.95 down to negative values. The corresponding hydrographs obtained using radar data show a broadly similar picture. For the stratiform period of January 1995, the variation in the peak flow is not so extreme, particularly when raingauge data are used, although the poor performance of the radar in January 1995 results in an ensemble of hydrographs containing double peaks, which leads to a large overall error. For the hydrographs obtained using raingauge data, Figs. 4(a) and 5(a), there appears to be no improvement in flow simulation from the grid squares containing multiple gauges. The variation in flow simulation accuracy appears, therefore, to be due largely to the spatial variation in the convective rainfall over the catchment rather than variation within a given square. Further work might explore how rainfall variability within a $2 \mathrm{~km}$ square affects catchment runoff for squares of high and low relief, making use of the two 8-gauge networks within the Brue catchment.

Figures 4(c) and 5(c) show how the root mean square error (rmse) in catchment runoff varies with time for the raingauge case, (a). The graphs suggest that a convective storm can lead to twice as much variation in the hydrograph as a stratiform storm; a rmse of $11.5 \mathrm{~m}^{3} \mathrm{~s}^{-1}$ in the convective storm is compared to $5.2 \mathrm{~m}^{3} \mathrm{~s}^{-1}$ during the stratiform storm. Plots of the 'rmse in runoff' against runoff, presented in Figs. 4(d) and 5(d), suggest that for the storms investigated here, the rmse is approximately proportional to runoff, with the overall relation being of the order of $1: 1$ for the predominantly convective period and a lesser proportion for the stratiform period, when the rmse is considerably less than runoff. Note the hysteresis effect with higher errors on the rising limb than on the falling limb of the hydrograph, reflecting the greater uncertainty generated by the fast response runoff and the lower uncertainty associated with the release of water from storage.

It is of interest to illustrate, and quantify, how variability in rainfall over the catchment transforms into variability in runoff at the catchment outlet. Figure 6 presents the variability in gauged rainfall as rmse time series and rmse versus magnitude plots. These correspond to parts (c) and (d)(i) of Figs. 4 and 5 , which present the resulting variability in catchment runoff. In forming rmse values, the error is defined with reference to the catchment average rainfall as 'truth'. The dimension of rainfall variability relative to runoff variability can be appreciated by noting that the conversion factor from mm (15 minute) ${ }^{-1}$ to $\mathrm{m}^{3} \mathrm{~s}^{-1}$ for the Brue catchment is 150 . Thus a peak rmse variability in 15 minute rainfall of $2 \mathrm{~mm}$ (Fig. 6 (a) (i)), or $300 \mathrm{~m}^{3} \mathrm{~s}^{-1}$, can be compared with a peak flow variability of $12 \mathrm{~m}^{3} \mathrm{~s}^{-1}$ (Fig. 4 (c)); the corresponding values for the stratiform period are $1.2 \mathrm{~mm}\left(183 \mathrm{~m}^{3} \mathrm{~s}^{-1}\right)$ and $5 \mathrm{~m}^{3} \mathrm{~s}^{-1}$. These statistics serve to highlight the significant damping effect of the catchment on the runoff response to rainfall and the lower variability in both rainfall and runoff response during stratiform as opposed to convective rain.

By way of summary of this part of the investigation, the distributed model is clearly sensitive to the location within the catchment of the grid-square raingauge data. As expected, the greater spatial variability in rainfall for the predominantly convective period is reflected in the wide variation in modelled hydrographs. Higher numbers of gauges in a grid-square do not appear to yield an improved model hydrograph, indicating that variability of rainfall at the catchment scale dominates over that at the grid scale. In the case of raingauge data, the grid squares whose rainfalls yield the poorest model hydrographs tend to lie to the east of the catchment, an area of higher relief, and result in an overestimation of flows. Clearly, a raingauge located in a higher relief part of the catchment, where rainfall is enhanced through the effects of orography, will be unrepresentative of the rainfall over the whole catchment. By contrast, in the case of radar, the grid squares whose rainfalls yield the poorest model hydrographs when applied across the whole catchment tend to lie to the west of the catchment. There is clearly scope for investigating in detail how the spatial organisation of rainfall, as opposed to the spatial variability in rainfall, impacts on the runoff response. Another important aspect is the influence of storm movement on catchment runoff production. These issues are beyond the scope of the present investigation but might be addressed through computer experiments aimed at removing the organisational and storm movement features apparent in the rainfall dataset and looking at how the 
(a) raingauge data

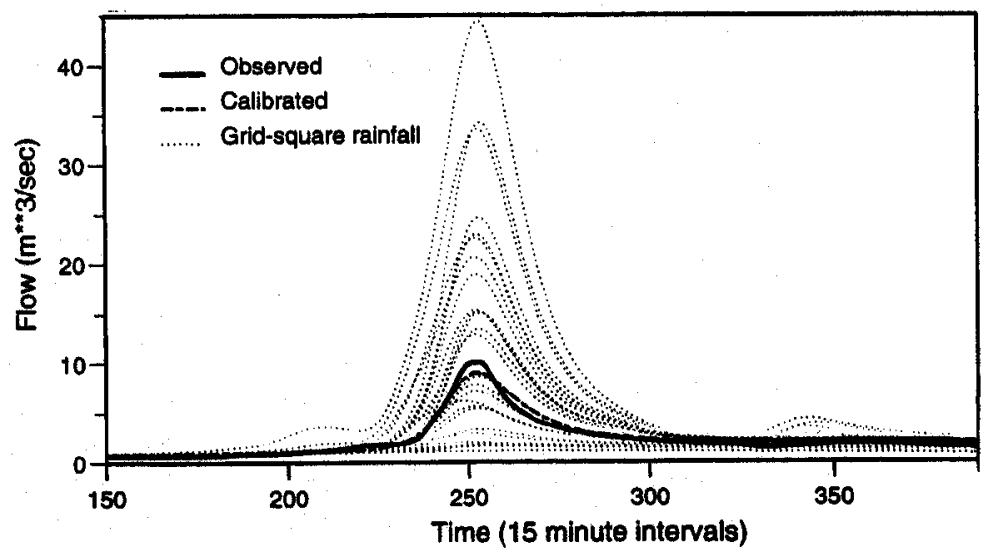

(b) radar data

(c) rmse (raingauge data)

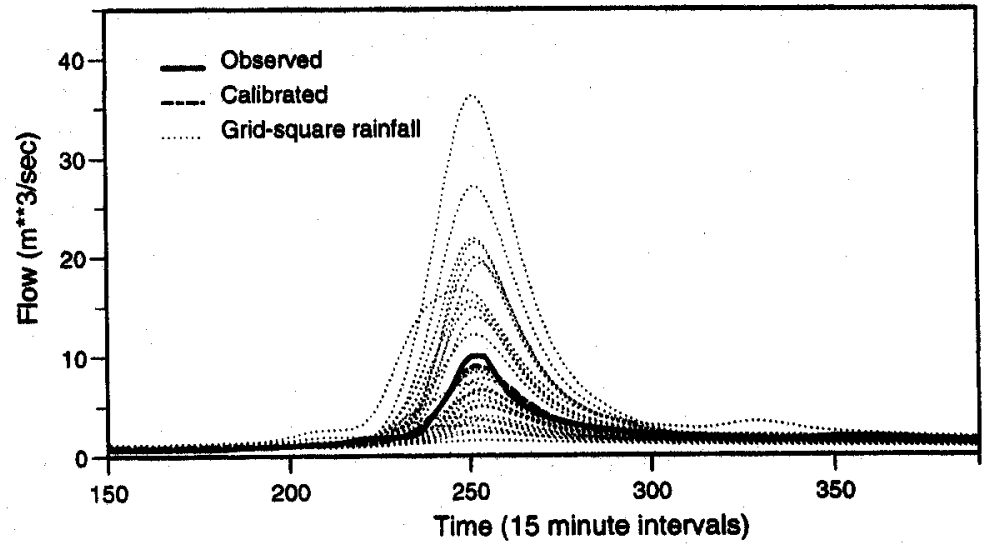

(d) rmse against runoff

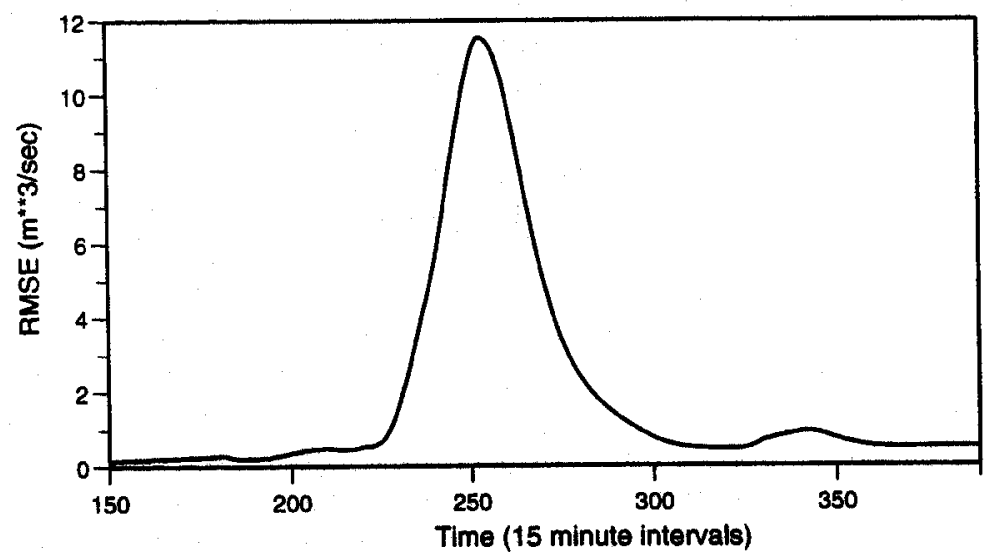

(i) raingauge data

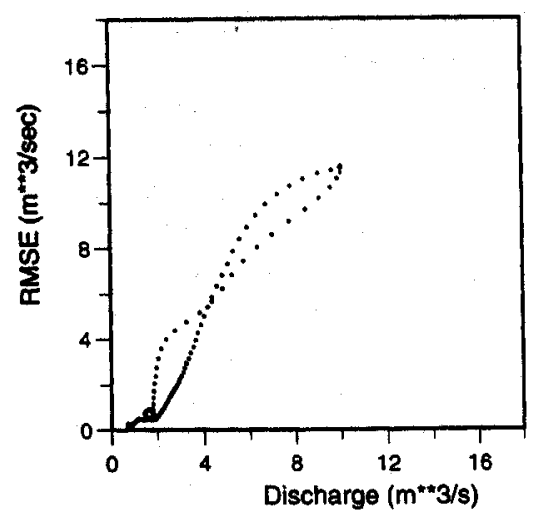

(ii) radar data

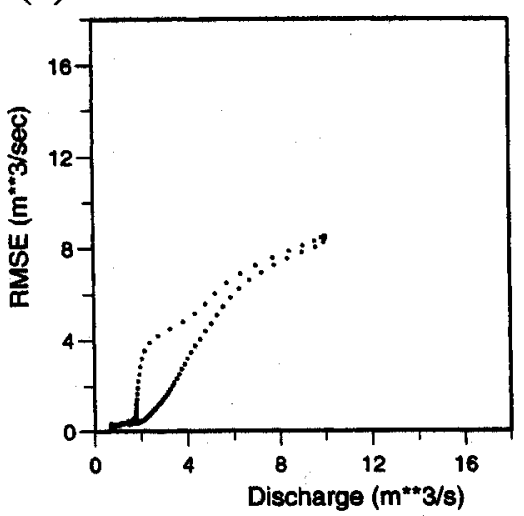

Fig. 4. Ensemble of hydrographs and runoff variability for convective rainfall period, 20-24 May 1994. 
(a) raingauge data

(b) radar data

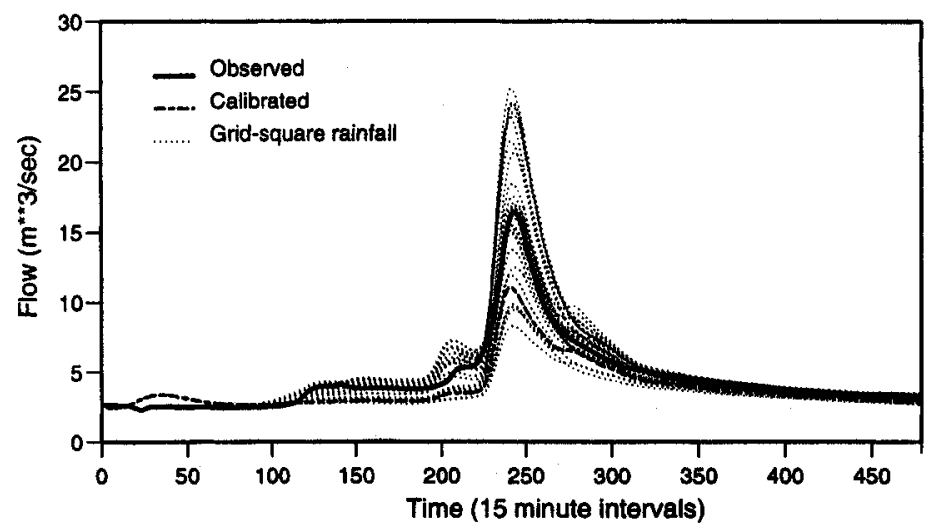

(c) rmse (raingauge data)

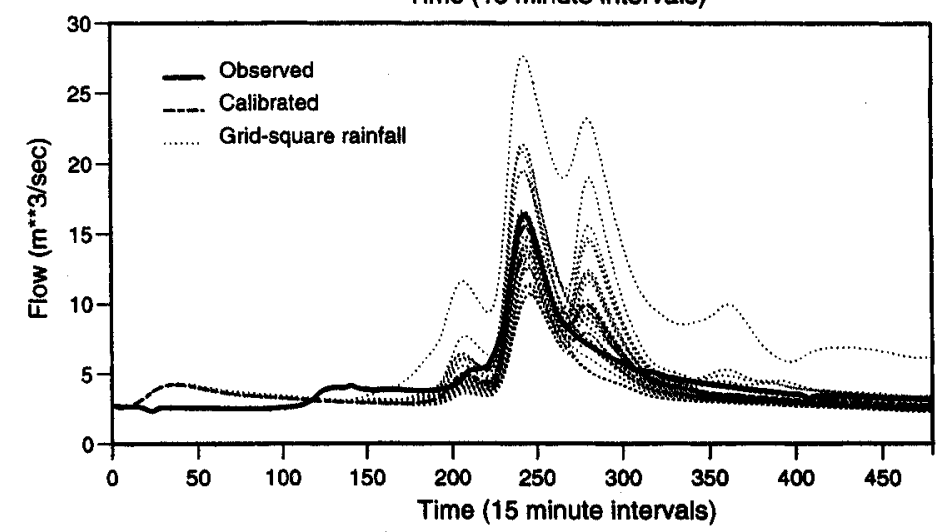

(d) rmse against runoff

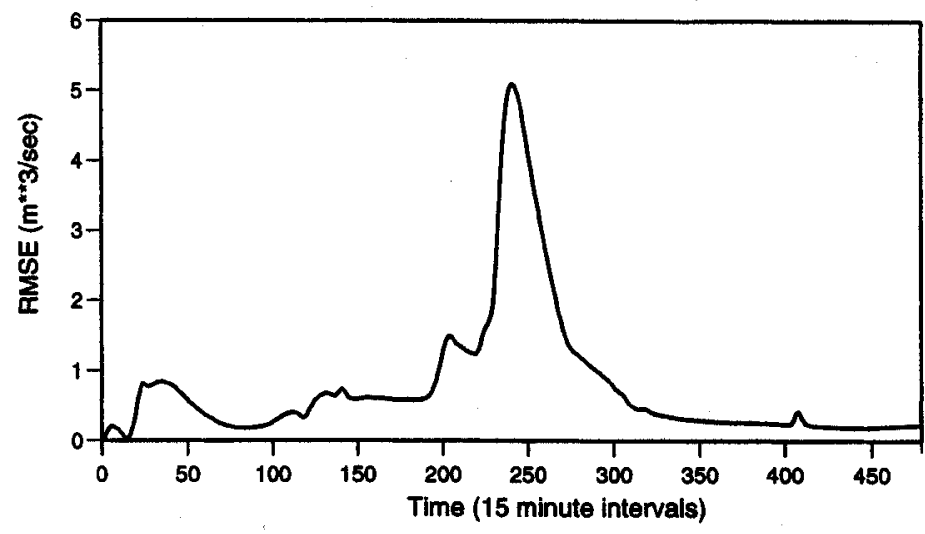

(i) raingauge data

(ii) radar data
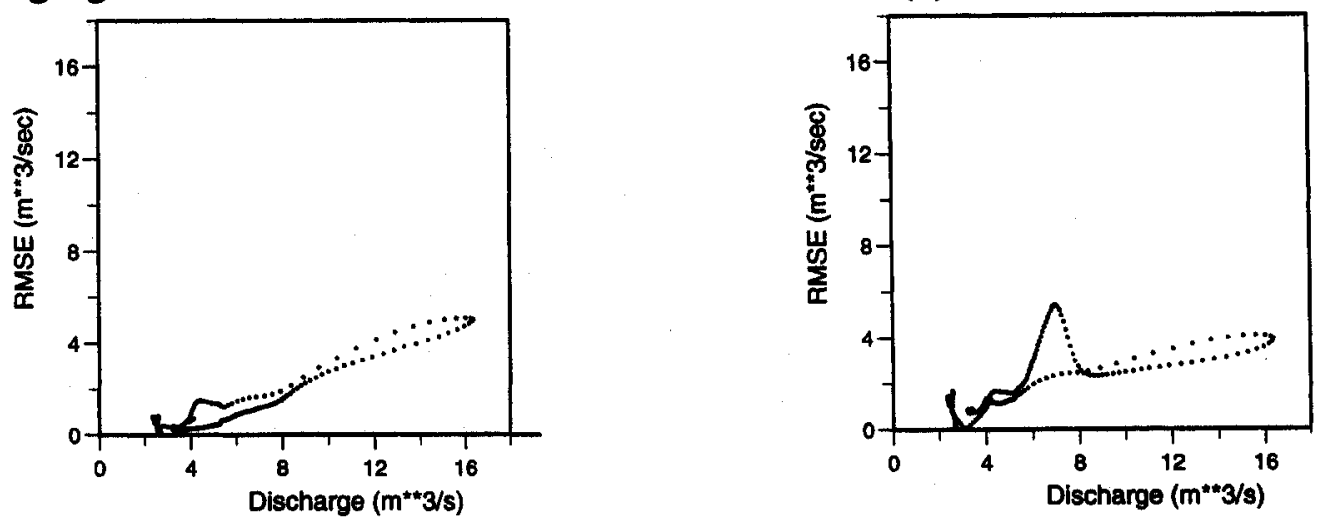

Fig. 5. Ensemble of hydrographs and runoff variability for stratiform rainfall period, 3-8 7anuary 1995. 
(a) convective rainfall period, 20-22 May 1994

(i) rmse

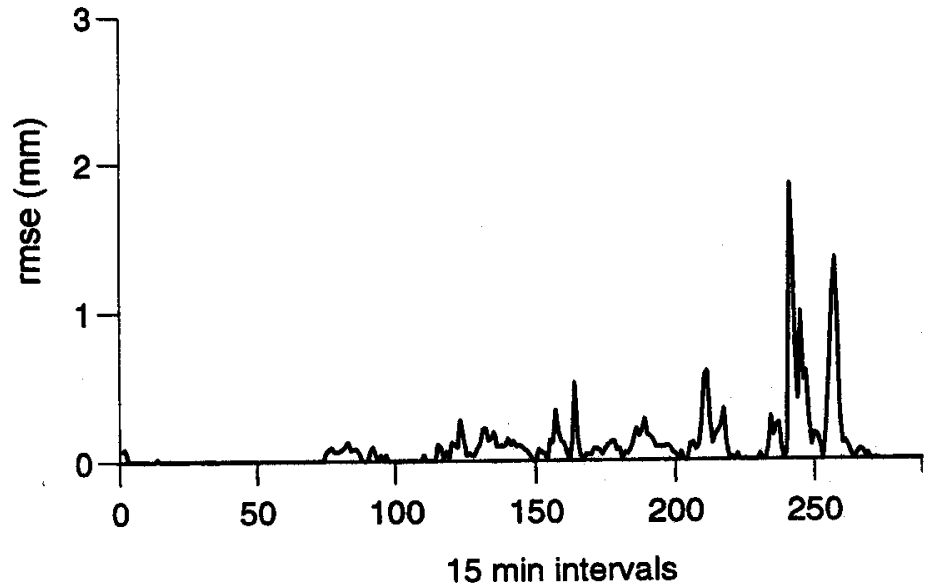

(b) stratiform rainfall period, 3-5 January 1995

(i) rmse

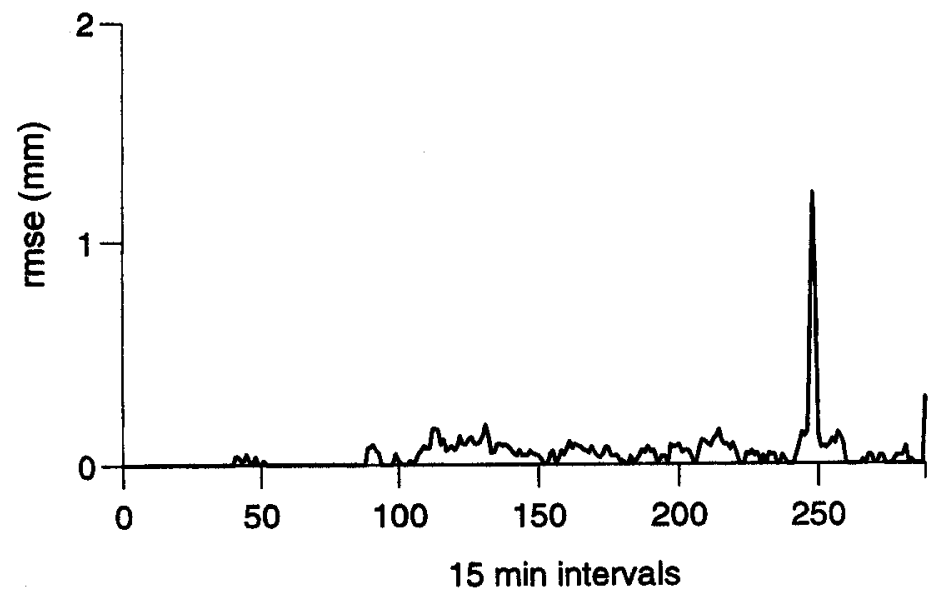

(ii) rmse against rainfall

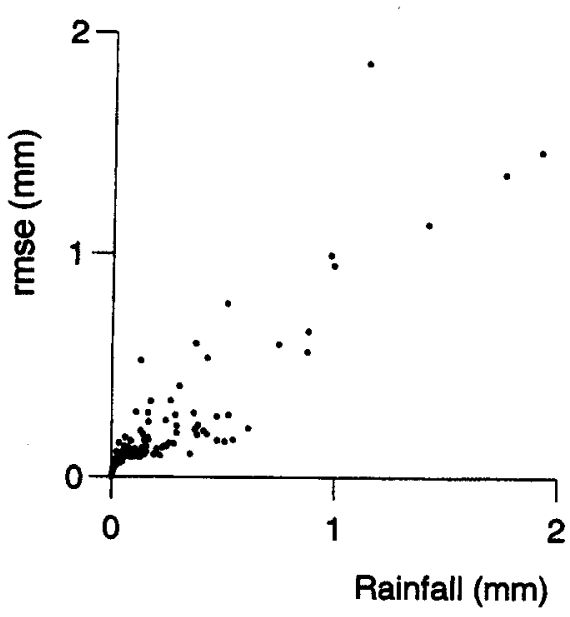

(ii) rmse against rainfall

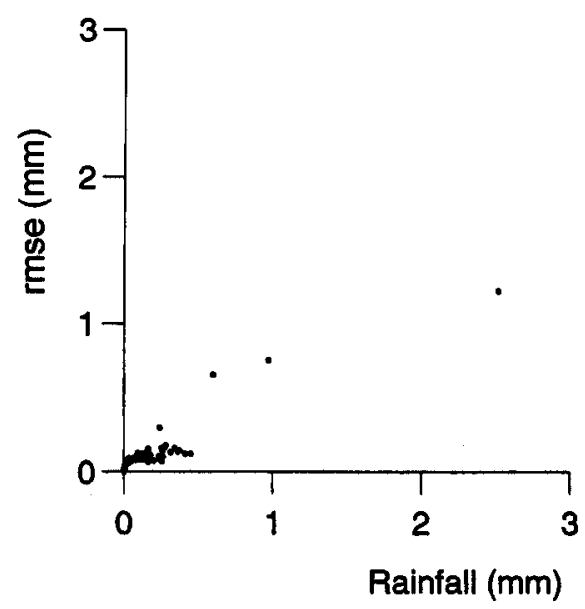

Fig. 6. Variability in raingauge rainfall corresponding to runoff in Figs 4 and 5.

runoff response changes. The results obtained for only two events are seen as indicative of the behaviour that might be expected from other events. Whilst other events have been analysed from the period of record 1993 to 1997 , there were few convective events generating significant runoff in the Brue catchment. The selection of just one stratiform and one convective event has also allowed results for each storm to be presented in a way that a more extensive investigation would not have allowed.

Having demonstrated the sensitivity of the distributed model to the spatial variability of rainfall, the model was run at three grid resolutions-2, 5 and $10 \mathrm{~km}$ - using the corresponding resolution of raingauge rainfall data to determine whether increased spatial resolution leads to a more accurate simulated hydrograph. This second part of the investigation, concerning the sensitivity of catchment runoff to spatial scale effects, forms the subject of the next section.
MODEL SENSITIVITY TO SPATIAL RESOLUTION OF MODEL AND RAINFALL DATA

To assess whether there is any benefit in using a distributed catchment model at a high rather than low resolution, the distributed model was run at a 2,5 and $10 \mathrm{~km}$ resolution using the corresponding resolution of raingauge and radar data. The model was initially calibrated at each resolution and for each type of rainfall data using a catchment average rainfall estimate; then distributed rainfall data were used as input to the model to assess the effect on the hydrograph. The model was calibrated a second time using distributed rainfall data to obtain the best possible flow result in each case.

To determine whether there is any benefit in using a distributed grid-based model over a more conventional lumped rainfall-runoff model, the lumped PDM catchment 
Table 1. Assessment of model accuracy ( $\mathrm{R}^{2}$ statistic) for different model and data resolutions, and comparison with the lumped PDM model.

(a) Mixed convective/stratiform period, 20 to 29 May 1994

\begin{tabular}{llllll}
\hline Rainfall data & \multicolumn{2}{l}{ Catchment average } & & \multicolumn{2}{l}{ Grid square } \\
Model & Gauge & Radar & & Gauge & Radar \\
\hline PDM & 0.909 & 0.832 & & - & - \\
SGM-2 km & $\mathbf{0 . 9 4 2}$ & 0.874 & & 0.929 & 0.804 \\
SGM-5 km & 0.937 & 0.888 & & 0.926 & 0.865 \\
SGM-10 km & 0.931 & 0.878 & & 0.953 & 0.821 \\
\hline
\end{tabular}

(b) Stratiform period, 6 February to 1 March 1995

\begin{tabular}{llllll}
\hline Rainfall data & \multicolumn{2}{l}{ Catchment average } & & \multicolumn{2}{l}{ Grid square } \\
Model & Gauge & Radar & & Gauge & Radar \\
\hline PDM & 0.911 & 0.750 & & - & - \\
SGM-2 km & 0.886 & 0.708 & & 0.890 & 0.730 \\
SGM-5 km & $\mathbf{0 . 9 2 2}$ & 0.729 & & 0.911 & 0.736 \\
SGM-10 km & 0.913 & 0.797 & & 0.907 & 0.777 \\
\hline
\end{tabular}

(a) Catchment average rainfall and $2 \mathrm{~km}$ model

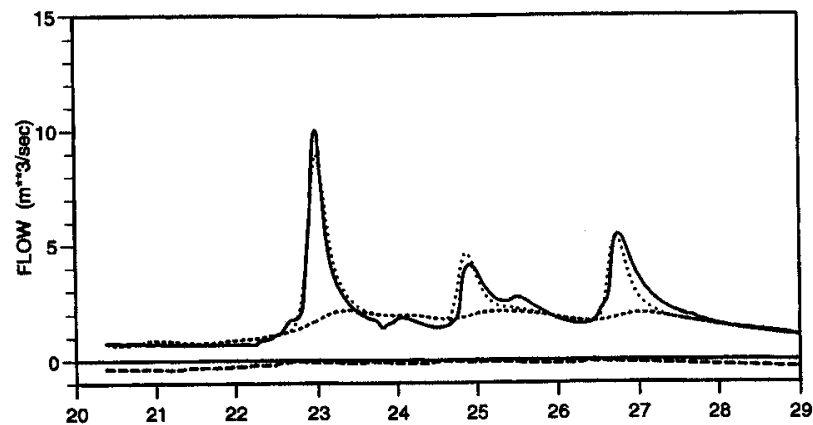

(c) Distributed rainfall and $2 \mathrm{~km}$ model

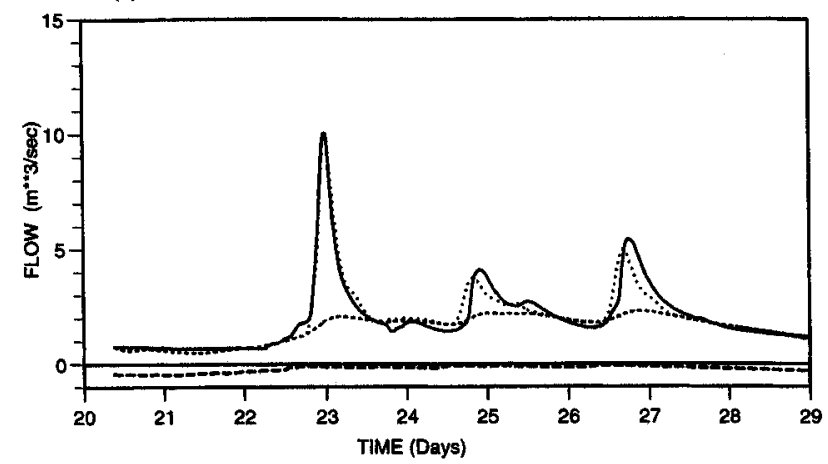

runoff model was applied alongside the distributed SGM, using catchment average rainfall data.

Two periods were used in the assessment:

20-29 May 1994: stratiform and convective rainfall 6 Feb to 1 Mar 1995: stratiform rainfall.

Flow simulation accuracy is summarised in Table 1 in terms of the $\mathbf{R}^{2}$ performance statistics. Each table is arranged in two sections corresponding to the distribution of the rainfall (catchment average or grid-square distributed) on which the rainfall-runoff model had been calibrated. In each case the best results are highlighted in bold typeface. Results for the PDM are only available using catchment average rainfall data because of the lumped nature of the model.

\section{Mixed convective/stratiform period, 20 to 29 May}

For this period, raingauge data gave the best model performance. When the SGM was used with radar data the resulting simulated flows tended to miss out the second of the three peaks in the hydrograph, whilst the PDM modelled all three peaks. There was no clear relation between spatial resolution and model performance, although the best overall performance was obtained using the $10 \mathrm{~km}$ resolution distributed model with raingauge data as input. Figure 7 presents a set of four hydrographs

(b) Catchment average rainfall and $10 \mathrm{~km}$ model

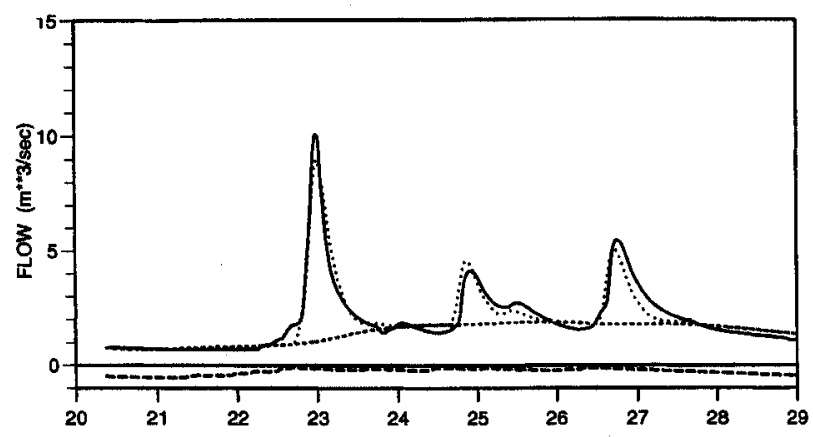

(d) Distributed rainfall and $10 \mathrm{~km}$ model

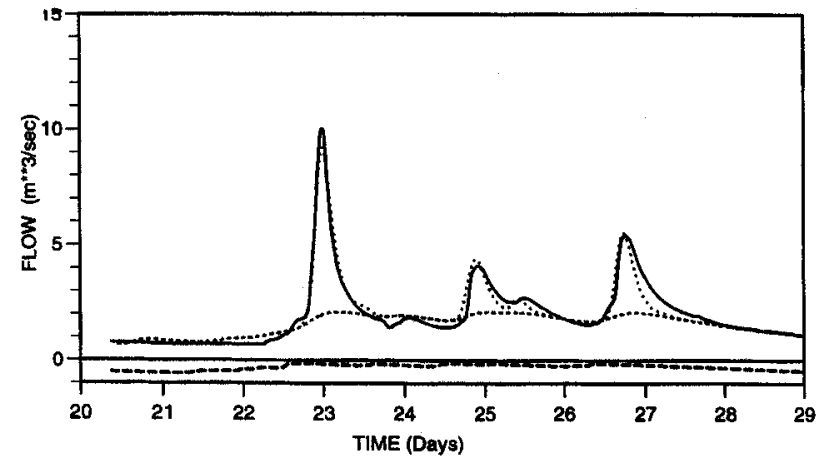

Fig. 7. Comparison of hydrographs obtained with catchment average and distributed rainfall data, from raingauges and radar, using 2 and 5 km resolution models: mixed convective-stratiform period (20-29 May 1994). 
obtained from models configured on a 2 and $10 \mathrm{~km}$ grid and using raingauge data, firstly in catchment average form and secondly as grid square estimates corresponding to the model grid size (i.e. 2 and $10 \mathrm{~km}$ ). The hydrographs are very similar, the main differences being in the simulation of the peaks and slight differences in their timing. The $10 \mathrm{~km}$ resolution results appear to simulate the timing of the second and third peaks with greater success than those obtained using $2 \mathrm{~km}$ resolution rainfall data, whilst the latter proves best in predicting the main peak.

\section{Stratiform period, 1 Fanuary to 1 March 1995}

The best overall flow simulation results were obtained using raingauge as opposed to radar data, and catchment average data in preference to distributed data. Surprisingly, the best results were not obtained using the most detailed model and data $(2 \mathrm{~km})$, but from the $S G M$ at a $5 \mathrm{~km}$ model resolution and with $5 \mathrm{~km}$ rainfall data as input. In the case of radar data, flow simulation accuracy seemed to increase with decreasing resolution. Figure 8 compares flow hydrographs using radar and raingauge data for the 2 and $5 \mathrm{~km}$ resolution models. The hydrographs in Fig. 8 (c) and (d) indicate that the $5 \mathrm{~km}$ resolution model and rainfall data simulated the largest peak on the 12 February most successfully, possibly in part due to the improved initial conditions. Calibration of the $5 \mathrm{~km}$

Catchment average rainfall: (a) Gauge data and $2 \mathrm{~km}$ model

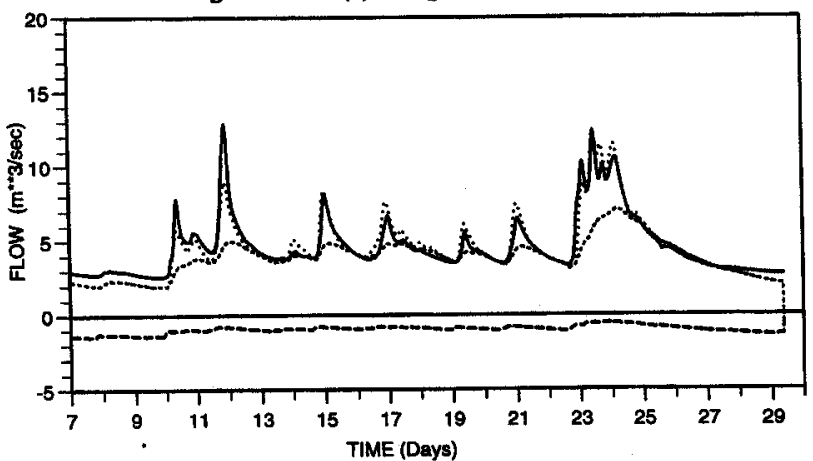

Distributed rainfall: (c) Gauge data and $5 \mathrm{~km}$ model

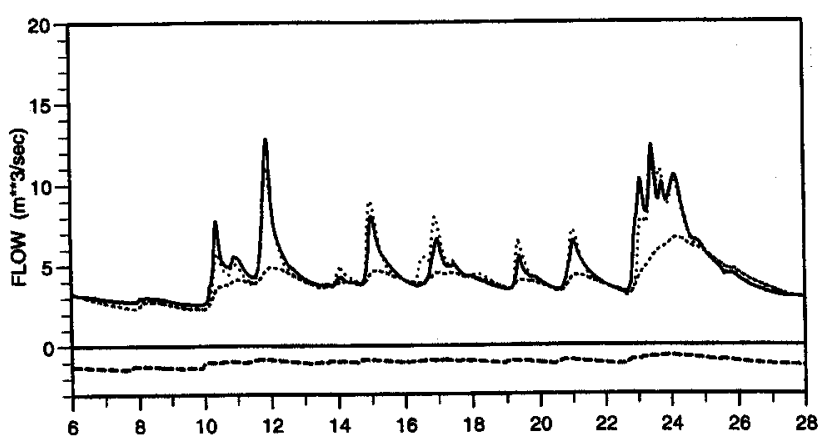

resolution model with radar data proved particularly difficult resulting in the poor hydrograph seen in Fig. 8(d).

Overall, as expected, the distributed Grid Model seems less sensitive to distributed rainfall data during stratiform rain than during more spatially variable convective rain. Changing from using catchment average to grid square rainfall data has most effect on the hydrograph for the convective event using a high resolution model, though recalibration returned the model performance to that obtained from catchment average rainfall data. Using distributed rather than catchment average rainfall data improved model performance in only one case: the $10 \mathrm{~km}$ resolution model with raingauge data as input. For the two events presented here, the lumped PDM model performed less well, but in other events not shown here, the PDM has performed as well and occasionally better than the distributed Grid Model.

To summarise, the lower resolution 5 or $10 \mathrm{~km}$ Grid Models appear to be the most robust for modelling flow in the Brue and often give the best simulation results. This is contrary to what was expected and may be due to the need for spatially invariant data in a model that is unable to reproduce the hydrological behaviour of the catchment. The apparent need for additional smoothing in both the model structure and rainfall input is commented on further in the concluding section. (b) Radar data and $2 \mathrm{~km}$ model

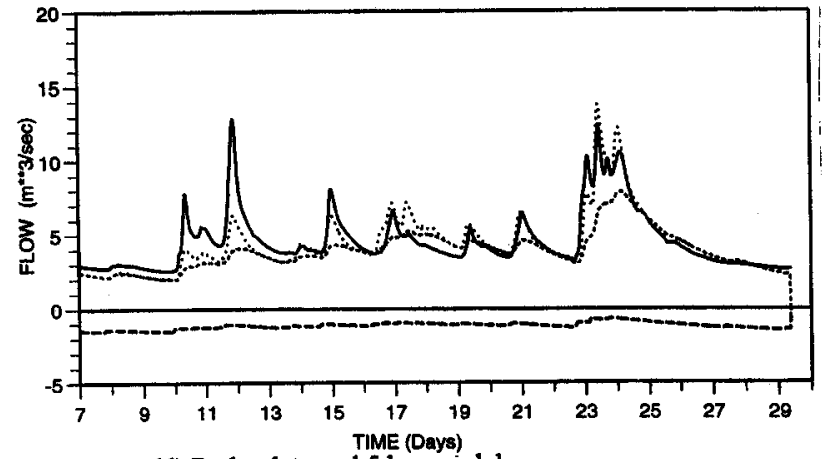

(d) Radar data and $5 \mathrm{~km}$ mode

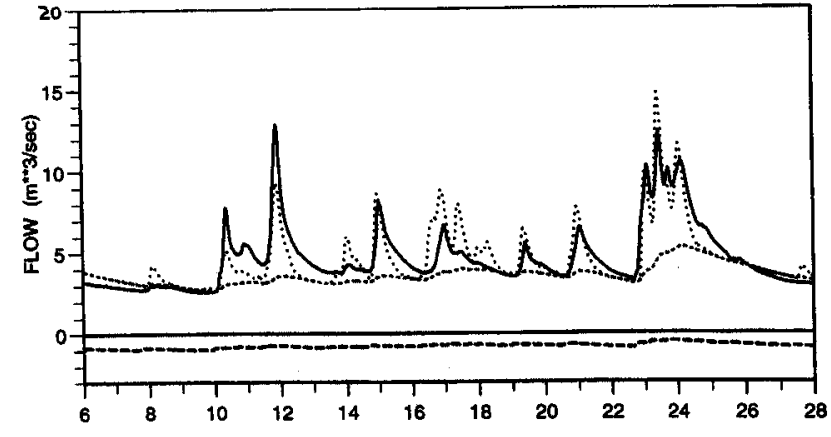

Fig. 8. Comparison of hydrographs obtained with catchment average and distributed rainfall data, from raingauges and radar, using 2 and 5 km resolution models: stratiform period (6 February-1 March 1995). 


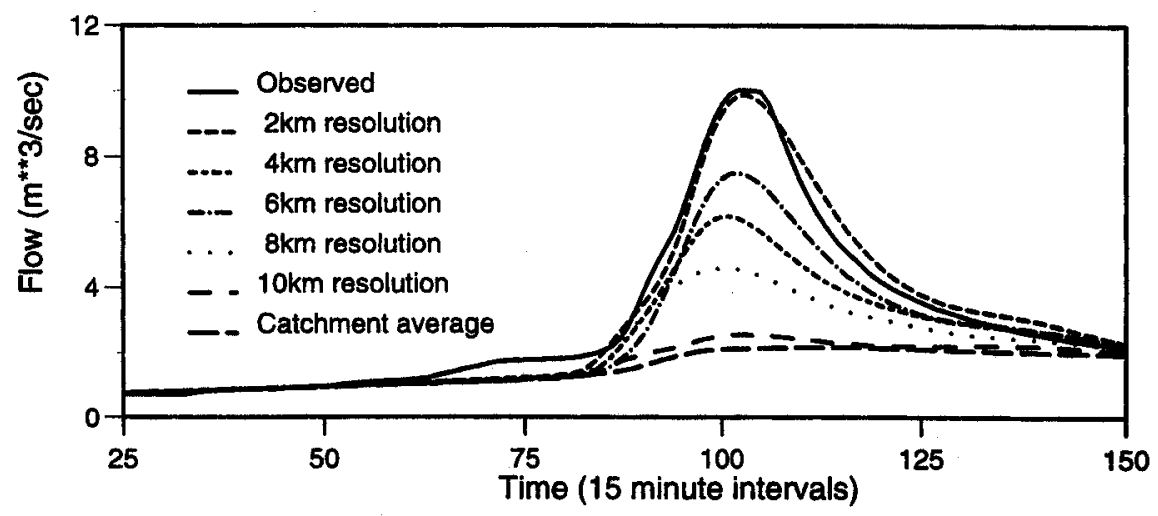

Fig. 9. Hydrographs obtained using different resolutions of raingauge data, 20-29 May 1994.

\section{MODEL SENSITIVITY TO RAINFALL DATA AT DIFFERENT SPATIAL SCALES}

The third part of the investigation aimed to assess the extent to which the improved performance obtained from the lower resolution models was due to the resolution of the model or the rainfall data. This was assessed by running the SGM at a $2 \mathrm{~km}$ model resolution with raingauge data (as the best possible source of rainfall) for a range of rainfall data resolutions: $2,4,6,8,10$ and $16 \mathrm{~km}$. The $16 \mathrm{~km}$ resolution corresponds approximately to catchment scale rainfall data.

The distributed model on a $2 \mathrm{~km}$ grid was calibrated using distributed $2 \mathrm{~km}$ grid-square raingauge data for two periods:

20-29 May 1994: predominantly convective rainfall 3-8 January 1995: stratiform rainfall.

Different resolutions of grid-square rainfall data were used as input to the $2 \mathrm{~km}$ model without further calibration. Then the model was calibrated a second time to identify the best model performance for each resolution of rainfall data. Results are presented for the May 1994 event in hydrograph form in Fig. 9, which shows how the flow peak reduces as the spatial resolution of the raingauge data decreases. After additional calibration for each resolution of raingauge data, the simulation accuracy improves to a level similar to that obtained using $2 \mathrm{~km}$ data. Figure 10(a) shows how there is little difference in $\mathrm{R}^{2}$ values for each spatial resolution of raingauge data after recalibration. For the more spatially homogeneous stratiform rainfall event of January 1995 there is little change in simulation accuracy with resolution of raingauge data, and Fig. 10(b) shows that the flow simulation accuracy is unaffected by changes in spatial resolution of rainfall data (hence results for recalibration are not shown here).

The results show that after calibration for each dataset, the highest resolution of data $(2 \mathrm{~km})$ still fails to improve on results obtained from the lower resolution grid square raingauge data $(8$ or $10 \mathrm{~km})$ which seem slightly better. For the stratiform rainfall event there is little decrease in model (a) convective-stratiform rain, 20-29 May 1994

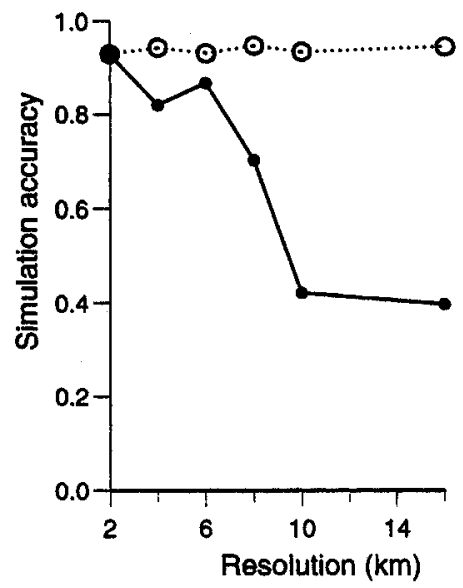

(b) stratiform rain, 3-8 January 1995

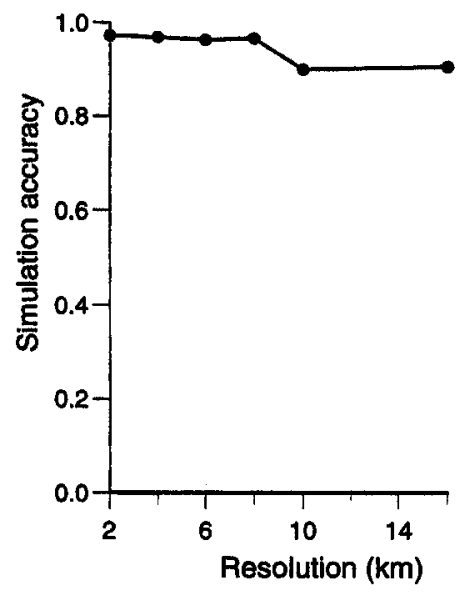

Fig. 10. Flow simulation accuracy $\left(R^{2}\right.$ statistic) against spatial resolution of rainfall data for mixed convective-stratiform and stratiform rainfall periods. Continuous line with dots: calibrated using $2 \mathrm{~km}$ rainfall data. Dotted line and open circles: recalibrated at each resolution of rainfall data. 
accuracy as the resolution of the rainfall data decreases, confirming previous results that the model is less sensitive to spatial rainfall scales in stratiform rain.

\section{Summary and Conclusions}

A distributed grid-based rainfall-runoff model has been assessed at a number of spatial scales using grid-square rainfall data obtained from a dense raingauge network and weather radar. Results show that the Grid Model using raingauge data as input is sensitive to the locations of raingauges within the catchment and hence to the spatial variability of rainfall over the catchment. This sensitivity is stronger for convective than for stratiform rainfall giving a broader spread of hydrographs in the convective case. Results show that for the rainfall periods studied, the root mean square error in the ensemble of hydrographs generated from grid-square rainfall data is twice as high in the convective than in the stratiform rain period, even though the flow peaks are of a similar magnitude; $10 \mathrm{~m}^{3} \mathrm{~s}^{-1}$ for the convective and $16 \mathrm{~m}^{3} \mathrm{~s}^{-1}$ for the stratiform storm.

An assessment of the Grid Model configured at different spatial resolutions with a corresponding resolution of gridsquare rainfall data showed the lower (5 and $10 \mathrm{~km}$ ) resolution models to be the most robust, and often the most accurate for simulating flow. To determine whether this surprising result was due to the resolution of the model or of the rainfall data, raingauge data at a range of spatial scales were used with a $2 \mathrm{~km}$ resolution model. The results showed that the lower resolution rainfall data generally gave as good a flow simulation as the higher resolution rainfall data. This result needs to be interpreted with caution in the context of the rainfall resolution requirements of a distributed rainfall-runoff model. It is clearly more appropriate for a distributed model to represent explicitly the smoothing effect of the catchment on the runoff response to rainfall than for the modeller to degrade the resolution of the rainfall data to achieve the same purpose. This puts the onus on seeking improvements to the rainfall-runoff model to make best use of the higher resolution rainfall data. The lumped PDM model used with catchment average rainfall performed less well than the distributed Grid Model for the two periods investigated here. This may not be the case in situations where rainfall is more sparsely or poorly measured when the PDM's robustness may prove of benefit.

Further work might determine whether the results obtained in this investigation apply to other model formulations, and might identify the most robust and reliable scale of rainfall-runoff model for different types of catchment and weather conditions. The present investigation has obtained illustrative examples of how rainfall variability, as sensed by radar and raingauges, feeds through to variability in modelled runoff response at the catchment scale. More extensive investigations would strengthen this understand- ing and provide additional guidance on the design of radar/ raingauge networks for flow forecasting and the spatial resolution requirements for rainfall at different catchment scales.

\section{Acknowledgements}

The Ministry of Agriculture, Fisheries and Food, under the Flood and Coastal Defence with Emergencies Division, supported this research together with Science Budget funding from the Centre for Ecology and Hydrology, and its predecessor the Institute of Hydrology.

\section{References}

Austin, R.M. and Moore, R.J., 1996. Evaluation of radar rainfall forecasts in real-time flood forecasting models. Quadermi $D_{i}$ Idronomia Montana, 16, 19-28.

Bell, V.A. and Moore, R.J., 1998a. A grid-based distributed flood forecasting model for use with weather radar data. 1: Formulation. Hydrol. Earth System Sci., 2, 265-281.

Bell, V.A. and Moore, R.J., 1998b. A grid-based distributed flood forecasting model for use with weather radar data. 2: Case Studies. Hydrol. Earth System Sci., 2, 283-298.

CEH Wallingford 2000. PDM Rainfall-Runoff Model. Version 2.0, CEH, Wallingford, UK.

Collier, C.G., 1996. Applications of meather radar systems: a guide to uses of radar data in meteorology and hydrology. 2nd edn., Wiley, Chichester, UK.

Faurès, J-M., Goodrich, D.C., Woolhiser, D.A. and Sorooshian, S., 1995. Impact of small-scale spatial rainfall variability on runoff modelling. 7. Hydrol., 173, 309-326.

Institute of Hydrology, 1992. PDM: $A$ generalised rainfall-runoff model for real-time use. Developers Training Course, National Rivers Authority River Flow Forecasting System, Version 1.0, Institute of Hydrology, Wallingford, UK. $26 \mathrm{pp}$.

Institute of Hydrology, 1996. A guide to the PDM. Version 1.0, January, $45 \mathrm{pp}$.

Moore, R.J., 1985. The probability-distributed principle and runoff production at point and basin scales. Hydrol. Sci. 7., 30, 273-297.

Moore, R.J., 1999. Real-time flood forecasting systems: Perspectives and prospects. In: Floods and landslides: Integrated Risk Assessment, R. Casale and C. Margottini (Eds.), Chapter 11, 147189, Springer.

Moore, R.J., Bell, V., Roberts, G.A. and Morris, D.G., 1994. Development of distributed flood forecasting models using weather radar and digital terrain data. R\&D Note 252, Research Contractor: Institute of Hydrology, National Rivers Authority, 144 pp.

Morris, D.G. and Flavin, R.W., 1990. A digital terrain model for hydrology. Proc. 4th International Symposium on Spatial Data Handling, Vol. 1, 23-27 July, Zurich, 250-262.

Obled, Ch., Wendling, J. and Beven, K., 1994. The sensitivity of hydrological models to spatial rainfall patterns: an evaluation using observed data. 7. Hydrol., 159, 305-333.

O'Connor, K.M., 1982. Derivation of discretely coincident forms of continuous linear time-invariant models using the transfer function approach. 7. Hydrol., 59, 1-48.

Pessoa, M.L., Bras, R.L. and Williams, E.R., 1993. Use of weather radar for flood forecasting in the Sieve River Basin: A sensitivity analysis. 7. Appl. Meteorol., 32, 462-475.

Singh, V.P., 1997. Effect of spatial and temporal variability in rainfall and watershed characteristics on stream flow hydrograph. Hydrol. Processes, 11, 1649-1669.

Watts, L.G. and Calver, A., 1991. Effects of spatially-distributed rainfall on runoff for a conceptual catchment. Nordic Hydrol., $22,1-14$ 
Wood, E.F., Sivapalan, M., Beven, K. and Band, L., 1988. Effects of spatial variability and scale with implications to hydrological modelling. 7. Hydrol., 102, 29-47.
Wood, S.J., Jones, D.A. and Moore, R.J., 2000. Accuracy of rainfall measurement for scales of hydrological interest. Hydrol. Earth System Sci., 4, 531-543. 